Celestinesca 33 (2009): 217-231 https://doi.org/10.7203/Celestinesca.33.20095

\title{
Hacia una datación de la Tragicomedia de Polidoro y Casandrina: datos históricos e influencias literarias
}

\author{
Carmen Solana Segura \\ Universidad de Huelva
}

\begin{abstract}
La Tragicomedia de Polidoro y Casandrina hallada en la Biblioteca Real en 1988 por Stefano Arata, fue adscrita al ciclo de las «Celestinas» y tanto el título como la datación ${ }^{1}$ se la debemos a él. Establece la fecha de composición en torno a 1564. Para ello se apoya en dos referencias a acontecimientos políticos que aparecen en la obra; la toma del Peñón de la Gomera en dicho año y una alusión relativa a la estancia de la Corte en Valladolid. También valora una mención genérica que se hace del rey "Don Felipe». No obstante, considero que hay ciertos claroscuros que deberían ser revisados, pues respecto a la cronología interna es imprescindible atender a otros indicios sincrónicos que se nos muestran en la obra. Para realizar un análisis más completo y estrechar aún más el círculo, distinguiremos dos apartados de argumentos para la datación. La cronología interna, que atiende fundamentalmente a cinco datos históricos ${ }^{2}$ concretos, y la externa, que construimos en virtud de las influencias literarias reflejadas en la Tragicomedia de Polidoro y Casandrina, asimismo con cinco aspectos destacables.
\end{abstract}

1.- Stefano Arata, "Una nueva Tragicomedia celestinesca del siglo XVI», Celestinesca, 12-1 (1988), pp. 45-50.

2.- Para la consulta bibliográfica de los datos históricos he contado con la generosa y experta ayuda del Dr. José Luis Sánchez Lora, profesor del Departamento de Historia II, Universidad de Huelva. 


\section{Datos Históricos}

\subsection{García de Toledo, marqués de Villafranca}

La toma del Peñón de la Gomera por el marqués de Villafranca es el acontecimiento político en el que Arata cimenta su datación. Para fechar la Tragicomedia de Polidoro y Casandrina, aparte de las consideraciones paleográficas, Arata toma como eje central una alusión que se hace en el texto, referente a la hazaña bélica antes mencionada y que él considera contemporánea a la época del autor. En la siguiente cita (Quinta Escena, Acto Segundo) aparece el personaje insigne, autor de tal suceso, Don García de Toledo:
...Con menos de cien mil hombres venció Leónidas al innumerable ejército de Jerjes. Y agora en nuestros tiem- pos, ¿no ganó a África cabeza de toda la berbería Don García de Toledo con seis mil hombres? Pues ¿por qué no podré yo contra dos idiotas en comparación de mi agudeza? [32 r].

En 1522, Muley Mohamed consiguió apoderarse del Peñón de Vélez de la Gomera. Cuarenta años más tarde, Don García de Toledo, Marqués de Villafranca y Virrey de Cataluña, recupera la titularidad para España por orden de Felipe II. Aunque, durante siglos esta titularidad fue virtual (sólo se empleó como presidio ocasional) y su abandono fue aprovechado por los piratas de la zona para establecer allí una de sus bases. ${ }^{3}$ García de Toledo, marqués de Villafranca, toma el Peñón de la Gomera en 1564, recibiendo en gratificación el cargo de virrey de Sicilia. Pero incluso, podría considerarse un margen de unos veinte o treinta años a partir de entonces, puesto que la expresión amplia de "en nuestros tiempos» acaso pudiera referirse a un momento algo posterior.

Por otra parte, otro miembro insigne dentro de la saga de los García de Toledo fue el nieto del anteriormente referido, el cual también llevó a cabo una hazaña en el norte de África, ya que en 1614 tomó la fortaleza de Larache. Capitán General de las galeras de Sicilia, fue aún más famoso que su abuelo, aunque históricamente al que se le da una mayor relevancia con respecto a la conquista de territorios en el Norte de África es al primero de los García de Toledo, debido al carácter propagandístico con que el monarca revistió su gesta. Así pues, la fecha establecida para la toma de Larache podría encajar perfectamente con el margen cronológico (1599-1626) de las manifestaciones literarias que veremos mas adelante.

3.- Véase, J. C. de la Cal, "Las otras 'Perejiles'. 1.000 islas que valen un reino", El Mundo, Publicación Digital, (2002). 


\subsection{La Corte en Valladolid}

Otro dato que Arata toma en consideración para su estudio (aparte de la mención genérica al rey don Felipe, que bien podría tratarse de Felipe II o III) es una alusión que se hace sobre la presencia de la Corte en Valladolid en el mismo momento en que expulsan a la vieja y hechicera Corneja de una mancebía, situada en dicha localidad. La cita es la siguiente:

RUFINO.- ...Llegada a los cincuenta y ocho años, vínose aquí, do sabrás que si yo la toco el pulso hará lo que sabe y te he dicho. [...]

RUFINO.- .... Acabada pues su vida, por restituirla su honra, estando allí la corte la sacaron con mas invenciones y libreas que yo sabría decir acompañada. [f.40v y $41 \mathrm{r}]$

Felipe II trasladó la capitalidad a Madrid en 1561, que es cuando ordena el traslado de la Corte a esta Villa. Sin embargo, en 1601, en tiempos de Felipe III, la Corte estuvo ubicada nuevamente en Valladolid y allí permaneció hasta $1606 .{ }^{4}$ Lo más probable es que se trate de la primera fecha, correspondiente al primer período en que la Corte estuvo instalada en Valladolid, a la que habría que añadir los veintinueve años que hacía que la vieja abandonó la ciudad, ya que en el presente de la obra tiene ochenta y siete años. De tal manera que la fecha interna rondaría el año de 1590.

Este dato de la Corte en Valladolid durante la estancia de la Corneja está íntimamente relacionado con el que desarrollaré a continuación y que bajo mi punto de vista podría ser el más representativo, pues se basa en un apunte sobre un lugar concreto, las afueras de la ciudad, exactamente el Humilladero de la Puerta del Campo, y la sustitución de una casa de mancebía de la que se tiene constancia histórica por un hospital, el de la Resurrección, del que también se tienen referentes históricos y literarios, pues aparece en una de las Novelas Ejemplares de Cervantes.

\subsection{El Hospital de la Resurrección}

En la Quinta Escena del Acto Segundo aparece un dato de suma importancia para establecer la cronología de la obra. Se menciona la expulsión de las prostitutas de una mancebía regentada por la vieja hechicera y prostituta Corneja para construir un Hospital de Infecciosos. Dicen los personajes: 
RUFINO.- Emendóse tanto que por hacer la penitencia con más aspereza, dio consigo en Valladolid y por no alquilar casa se retrujo a una ermita, que solía estar junto al humilladero de la Puerta del Campo, donde pasó la flor de su juventud, con tanta honra y aceptión de todos, que quien no llegaba a tocalle en la ropa, pensaba que perdía perdones... Llegada a los cincuenta y ocho años, vínose aquí, do sabrás que si yo la toco el pulso hará lo que sabe y te he dicho.

TRISTÁN.- ¿Pues por qué se vino?

RUFINO.- Pues todo lo quieres saber, porque las tomaron la ermita por fuerza,para hacerla hospital de bubas, porque nunca faltase tanto bien de aquella casa, y esto hicieron] a su ruego, porque quedase memoria de sus personas. [f.40r y 40v]

Dicho hospital no es otro que el Hospital de la Resurrección, el mismo que Cervantes toma como escenario para su novela de El Casamiento Engañoso. ${ }^{5}$ Durante su estancia en Valladolid Cervantes vive al lado del Hospital, ${ }^{6}$ cerca del puente sobre el Esgueva.

En 1541 la ciudad de Valladolid siente la necesidad de concentrar sus hospitales. El Consejo Real aprobó la iniciativa. Según García Oro «...se pensó que el lugar ideal para la nueva sede sería la concurrida Puerta del Campo. En este paraje... estaba ubicada la mancebía... En consecuencia se imponía un acuerdo: la ciudad compraría la casa de la mancebía y pagaría al Hospital las rentas que cosechaba en este paraje...Trasladaría a otro lugar más alejado el prostíbulo e instalaría un nuevo Hospital en la antigua casa de la mancebía vallisoletana. Se firmó el acuerdo el 14 de Febrero de $1541 \ldots{ }^{?}$.

Finalmente, el Hospital de la Resurrección fue fundado en 1553, en la casa que hasta entonces había sido la Mancebía de la ciudad y que era propiedad del Municipio. ${ }^{8}$ Según Alonso Cortés las obras de este hospital debieron comenzar hacia los años de 1563 a $1565 . .^{9}$ Así pues, según estos datos, la anciana tenía 58 años cuando salió de Valladolid y no aban-

5.- «El Hospital de la Resurrección, derribado en 1890, tenía en la portada un nicho con la fecha 1579». Véase Miguel de Cervantes, Novelas Ejemplares, ed. J.B. Avalle-Arce, Clásicos Castalia, Madrid, 1987, 3 vols.

6.- A. Gutiérrez Alonso y J. J. Martín González, Historia de Valladolid. IV. Valladolid en el siglo XVII, Ateneo, Valladolid, 1982, pp. 34-35

7.- García Oro y M. J. Portela Silva, «Felipe in y el problema hospitalario: reforma y patronato», Cuadernos de Historia Moderna, 25 (2000), pp. 87-124.

8.- «El archivo del Hospital de la Resurrección de Valladolid, incorporado al histórico provincial y universitario", Boletín de Anabad, Año xxviII- Núm. 4.

9.- L. Cortejoso, «Los Hospitales de Valladolid en tiempos de Felipe III", Archivos iberoamericanos de historia de la medicina, 12, 133 (1960), p. 142. 
donó la mancebía hasta que el hospital estuvo construido, entre 1563 y 1565. En efecto, según Cotejoso... «las mujeres publicas fueron expulsadas violentamente del lugar que ocupaban, se hizo el traslado rápido de los enfermos a los que habían sido locales de placer...». ${ }^{10}$ En resumidas cuentas, si a los 87 años ${ }^{11}$ que tiene la vieja en la actualidad de la obra le restamos los 29 que hace que salió de Valladolid, y a estos le sumamos la fecha de construcción del hospital, podemos suponer que la acción habría que situarla en un intervalo que oscilaría entre 1592-1594. Como vemos, resulta ser un argumento similar al establecido en el apartado anterior.

\subsection{El Destierro de los Tercios de Nápoles.}

La referencia al «destierro» de los tercios de Nápoles, aunque pasa casi desapercibida en la obra y no es un dato excesivamente consistente, sin embargo, sirve de apoyo para confirmar la cronología que se maneja en los dos apartados anteriores. Entre los consejos que Salustio da a su amo para que tome lacayos a su servicio y las prevenciones que debe tener con ellos, juega un papel importante la indumentaria de los mismos, que en la inmensa mayoría de los casos es de segunda mano y tiene tanto tiempo como años hace que «desterraron a los soldados de los tercios en Nápoles». Se refiere así

...Pues, qué diré de la capa porque no hay piojo por buenas uñas que tenga que se pueda tener en ella dos pasos, pues qué las calzas tan acuchilladas, que después de haber desterrado la mayor parte de los soldados del tercio del Reino de Nápoles, han servido de espantajo, de las higueras... [f.34r]

En 1567 cuando comienza la intervención contra los rebeldes flame cos al mando del Duque de Alba, ${ }^{12}$ los Tercios inician su éxodo hacia los Paises Bajos desde Italia y no regresan hasta $1577 .{ }^{13}$ Asumiendo que ha pasado el tiempo suficiente como para que un hecho histórico sea sinónimo de antigüedad, a la capa en cuestión, que ya ha tenido otros usos y está vieja, podríamos concederle un margen de unos veinte o treinta años desde su confección a raíz de la fecha del destierro, con lo cual nos colocaríamos en una cronología próxima a la que se ha llegado anteriormente.

\section{0.- Cortejoso, ob.cit., pp. 143.}

11.- Dice: «Hijo, tengo ochenta y siete para las siete horas de Dios, que no me faltan tres días» [f.55r].

12.- Julio Albi de la Cuesta, De Pavía a Rocroy. Los Tercios de infantería española en los siglos XVI y XVII, Balkan, Madrid, 1999, comenta al respecto: «En 1567 salen de Nápoles diecinueve compañías de tres mil doscientas treinta plazas al mando de Ulloa».

13.- R. Quatrefages, Los Tercios, Madrid, Fundación Universitaria Española, 1983. pp. 20-21. 


\subsection{Llega oro del Perú}

En la Tercera Escena del Acto I «traen a Polidoro grandes riquezas de Indias» y con esta mención obtenemos nuevas referencias para elaborar la cronología de la Tragicomedia. El texto completo es el siguiente:

MAYORDOMO.- Dios acreciente tu estado, bien afortunado señor. Agora me acaba de llegar esta carta de tu siervo el fator, que en Sevilla tienes, en la cual dice, como los días pasados llegaron tres naos del Perú en las cuales te vinieron ciento y cincuenta mil ducados, en barras de plata y oro, sin otras muy grandes riquezas que para ti vienen. Y más escribe: que agora nuevamente se te ha descubierto otra nueva mina en tu tierra, la más rica que se ha visto en aquellas partes. Por tanto, es menester mandar aparejar las acémilas y enviar con ellas hombres de recado, para que lo traigan. [f.20r].

Las tres naos que llegan de Perú cargadas de plata y oro sólo pueden proceder de una mina, El Potosí, que fue descubierta casualmente en 1545 por el indígena Diego Huallpa y que protagoniza el hallazgo de importantes vetas argentíferas en el monte llamado Sumaj Orcko ("El cerro magníficon), bautizado al poco tiempo como Cerro Rico. El Potosí produjo el $80 \%$ del total de la plata que se extrajo en el Perú y el $50 \%$ de toda la que se obtuvo en el mundo a fines del siglo XVI.

La otra mina nueva a la que hace referencia el manuscrito puede que fuera la de Huancavelica, descubierta en 1566 por el encomendero Amador Cabrera. ${ }^{14}$ Según Vilar "...después de 1580, la afluencia impetuosa de la plata americana dio, por un tiempo, la ilusión de una fuente inagotable». ${ }^{15}$ Aunque en muchos casos las catástrofes naturales desviaran el destino de las riquezas y dejasen en la ruina a los particulares tal y como le sucede a Polidoro al final de la obra.

Este historiador sostiene que las importaciones de metales preciosos en España, tanto por parte de los particulares como de la cantidad asignada a la corona, tienen su punto álgido durante la década que va de 1581 a

14.- "Cuenta la tradición que la famosa mina de mercurio fue hallada en 1566 por el encomendero Amador Cabrera, gracias a la información proporcionada por Ñahuincopa, un indígena que de esta manera quiso agradecerle el no haber maltratado a su hijo, luego de que éste extraviara el sombrero de su patrón durante las celebraciones del Corpus Christi en la ciudad». Véase Gabriel Bernat, "La minería colonial en la América española», Publicación Digital, (2002).

15.- Pierre Vilar, Oro y moneda en la Historia 1450-1920, Ariel, Barcelona, 1974, pp. 212 y ss 
1591. ${ }^{16}$ Después de 1600 las minas decaen. Para que en el imaginario colectivo del que el autor formaba parte constara tal excedente de riquezas, debían de haber pasado al menos una o dos décadas Además, el tópico "vale más que un Potosí» no es anterior a 1600. Con estos datos volvemos a aproximarnos a la primera década del siglo XVII.

\section{Datos Literarios}

Aparte de la cronología que nos aportan los datos históricos, por los que podemos situar el texto entre la última década del siglo xvi y la primera del XVII, es imprescindible hacer una revisión de aquellos aspectos literarios que encontramos en otros autores coetáneos y que nos dan claves más o menos precisas para datarlo. Los tres primeros datos están directamente relacionados con el auge de la novela picaresca, cuya cimentación como género corresponde a la primera década del siglo XVII.

\subsection{Aparece el término "picaro" aplicado a un tipo literario determinado}

Según Rutherford, en la literatura española del siglo xvi hay multitud de situaciones picarescas en las que no se emplea ni una sola vez la palabra pícaro. No aparece en el Lazarillo de Tormes (1554) ni en la Tragicomedia de Calisto y Melibea, ni en ninguna de sus imitaciones. ${ }^{17}$ Pero sí lo hace en esta tardía quinta continuación de la Tragicomedia de Rojas, ${ }^{18}$ un texto que evidentemente no conoce el estudioso. Si tenemos en cuenta que este término aplicado a un tipo social concreto solo se consagra con la aparición del Guzmán de Alfarache en 1599, habremos dado con la clave para fechar acaso esta obra en la primera década del siglo XVII.

En el siguiente fragmento Salustio, criado fiel de Polidoro, nos hace una descripción fidedigna de dos pícaros, los lacayos de su amo, Tristán y Rufino

SALUSTIO.- Las piernas traigo quebradas de buscar aquellos azotadizos. Mal hayan cuantos rollos hay en esta tierra, porque no los tienen a miradero. Que merecían pringarlos a los ganapanes bautizados, sucios, que después que se ven privados se alzan a mayores.

16.- Vilar. ob. cit. pp. 197-199.

17.- John Rutherford, Breve historia del picaro preliterario, Oviedo, Universidad de Oviedo, 2001, pp. 33-35.

18.- Ana Vian Herrero, «La Tragicomedia de Polidoro y Casandrina: relación cíclica y caminos de la parodia”, Criticón, 87-88-89 (2003), pp. 899-914. 
Yo aseguro que no falten ellos a la hora del comer. Nunca supieron sino tragar polvo del almohaza. Y nunca se vistieron, sino de mantas de caballos. Y agora que se ven con librea, deben de ser idos a dar vistas, pues mal me andarán las manos, o yo dejarretaré el negocio, de suerte que no lleguen adelante con él, como piensan. Mas que digo, quiero ir aquella taberna, que tales pícaros son, que allí se han de hallar o en los bodegones... [f.54r]

Existía un tipo determinado de pícaro, el pícaro de corte, ${ }^{19}$ cuyo significado era "hombre de baja condición social» y que se oponía al cortesano con los valores morales y sociales que ello implicaba. De pícaros y buscavidas que se desplazaban de modo itinerante estaban repletas las dos ciudades en las que se instalaba la Corte en esta época y puede que en la ciudad en la que transcurren las vicisitudes de los enamorados protagonistas, Casandrina y Polidoro, fuese una de ellas.

De las Cortes se habla también en el Buscón, cuya primera redacción se sitúa entre 1603-1604, cuando se refieren a la vestimenta de los pícaros, «... en la Corte hay siempre [...] unos géneros de gentes como yo, que no se les conoce raíz ni mueble, ni otra cepa de la que deciden los tales...». ${ }^{20} Y$ como veremos en el apartado siguiente, en términos parecidos habla Tristán del atuendo desaliñado de los pobres pajes que pululan en torno a la misma.

Asimismo, resulta curiosa la concomitancia temática con El casamiento engañoso de Cervantes, publicado en 1613. ${ }^{21}$ En ella también aparece el Hospital de la Resurrección. Se abre con el encuentro en Valladolid de dos antiguos amigos el alférez Campuzano y el licenciado Peralta, no obstante, lo más curioso es que el momento histórico de la novela coincide con la estancia de Cervantes en dicha ciudad desde 1604 a 1605 y que su percepción de la ciudad como realidad social y urbanística corresponde a una época en que las Cortes eran el centro de la ciudad.

Otro pícaro cuya historia culmina con prosperidad y buena fortuna después de los avatares acaecidos en su vida, es Lázaro de Tormes que residirá felizmente casado en la ciudad de Toledo en plena celebración de las Cortes.

\subsection{Una similitud con $\mathrm{El}$ Buscón: la vestimenta del pícaro}

La configuración del pícaro como personaje harapiento, sucio y ladrón de viandas también se confirma en esta obra. En el siguiente fragmento

19.- John Rutherford, ob. cit., pp. 40-41.

20.- Florencio Sevilla, La Novela Picaresca Española, Castalia, Madrid, 2001, p. 586.

21.- Miguel de Cervantes, ob. cit., p. 20. 
veremos bastantes paralelismos con el capítulo sexto del Libro Segundo y el capítulo primero del Libro Tercero de La vida del Buscón.

Tristán y Rufino, envidiosos de Salustio por haber recibido dinero de su amo, idean un plan para Polidoro: «revolverle con una mujer hermosa, hija de una gran hechicera». El primer paso para ello es aconsejar a su señor que tome las riendas de su casa y ponga a su servicio más pajes y lacayos que cumplan con ciertos requisitos. Comenta Tristán a su amo:

... Señor, lo primero es de saber qué orden tomarás en tu casa como quien hace libro nuevo en pompa, así como en gravedad, y gasto de tu casa, y es necesario que de aquí adelante, tengas muchos pajes, y muchos lacayos, pero no los has de traer como lo traen otros muchos, que los traen rotos, desconfiados y descalzos, puesto caso que aunque seas más liberal, en ser pajes traen esto consigo, juntamente con otra pasión que es sarna y pobreza, que más ciertas son estas gracias en los pajes, que la picaza en el soto $¡ \mathrm{Oh}$, pobres pajes que no hay ninguno de vosotros que no le hayan cardado! Y teniendo la gorra, cuántos gorreros de viejo hay en la corte, pues la camisa que traen es donosa, porque no hay ninguno de ellos que desde que se la vista nueva, hasta que la desecha no se la muda. Pues, qué diré del sayo, o de la capa, porque jubón no le tienen, :pasáis por tal cosa que como no le tienen, dicen que es grosería traerle con el calor? Pues, qué diré de la capa porque no hay piojo por buenas uñas que tenga que se pueda tener en ella dos pasos, pues qué las calzas tan acuchilladas, que después de haber desterrado la mayor parte de los soldados del tercio del Reino de Nápoles, han servido de espantajo, de las higueras, de antibol. Y en rompiéndoseles la media, luego anda el pañizuelo o el tafetán, que para este propósito en su desembarazada arca guardan los zapatos que mientras les dan otros, gastan el cuero de los pies y cuando se los vienen a dar, los arpan de manera por abajo, y por arriba, que están seguros que por faltas de ventanas no deje de salir el mal humor, pues cuando ya se le parece a la pobre capa la superficie, el nuevo tinte dicen, sus, hágase sayo, y porque no se corrompa de allí va a jubón, y tras esto ha aforro de sayo y al último viene a servir de soletas de calzas porque los dineros que costó no vayan mal logrados, y mal empleados, de manera que su mayor gloria es traer luto porque ya con aquello, encubren sus manifiestas mancillas, pues cuando viene la librea no 
hay pariente pobre, quédales que dirigir hartos días. Y son $\tan$ locos que, si les dan tiras, que son pocas veces, las pican porque parezca que no es librea, sino invención sacada a su costa. Pues, si digo del comer ellos mesmos, $y$ el gato comen en un plato, el remedio que hallan, es menester callar de vergonzoso pero con todo esto digo, que esconden la perdiz, y la tortilla de los guevos, y cualquier otra cosa que alcanzan de la mesa, en la bragueta o debajo de la gorra, y cuando meten el servicio dan con la escudilla de manjar blanco, en la pared del repostero, y tienen otros muchos vicios, y siniestros tales que están a pared y medio de ganapanes, así que con todo esto remediando tú lo que en tu mano estuviere, no dejes luego de ponerte a gesto recibiendo criados, pues tan cargado estás de prosperidad, porque te hago saber que en ninguna cosa se conoce mas que en tener mucha gente a quien mandar. [f. 33v- 34v]

Observemos ahora las similitudes con el capítulo sexto del Libro Segundo ${ }^{22}$ de La Vida del Buscón: ${ }^{23}$

Lo primero, ha de saber que en la Corte hay siempre el más necio y el más sabio, más rico y más pobre... y que en ella hay unos géneros de gentes como yo, que no se les conoce raíz ni mueble, ni otra cepa de la que deciden los tales... es gran trabajo traer la comida en manos ajenas. Somos susto de los banquetes, polilla de los bodegones, cáncer de las ollas y convidados por fuerza... Pues ¿qué diré del modo de comer en casa ajenas? En hablando a uno media vez, sabemos su casa, vámosle a ver, y siempre a la hora de mascar, que se sepa que está en la mesa... Tenemos de memoria, para lo que toca a vestirnos, toda la ropería vieja. Y como en otras partes hay hora señalada para oración, la tenemos nosotros para remendarnos... Es de ver cómo quitamos cuchillas de atrás para poblar lo de delante; y solemos traer la trasera tan pacífica, por falta de cuchilladas, que se queda en las puras bayetas... bien ve vuestra merced — dijo — esta ropilla; pues primero fue gregüescos, nieta de una capa $\mathrm{y}$ bisnieta de un capuz, que fue en su principio, y ahora

22.- Florencio Sevilla, ob. cit., pp. 585-587.

23.- Según Lázaro Carreter, la primera redacción se sitúa en el bienio 1603-1604, mientras que la segunda entre 1609-1614. Francisco de Quevedo, La Vida del Buscón, ed. Lázaro Carreter, Barcelona, Planeta, 1982, p. XXXVII. 
espera salir para soletas y otras cosas... Y al fin, señor licenciado, un caballero de nosotros ha de tener mas faltas que una preñada de nueve meses y con esto vive en la Corte...

Además, en el capítulo primero del Libro Tercero se añade:

... hallé que debajo de la sotana traía gran bulto. Yo pensé que eran calzas, porque eran a modo dellas, cuando él, para entrarse a espulgar, se arremangó, y vi que eran dos rodajas de cartón... vengo del camino con mal de calzas, y así me habré menester recoger a remendar... y que por falta de harapos se estaba, quince días había, en la cama, de mal de zaregüelles...

Parece ser, en efecto, que tanto los pícaros del Buscón como los de la Tragicomedia comparten determinadas características inherentes a la concepción del pícaro literario. De esta forma, ambos comparten los piojos, el hurto de alimentos, la ropa o zapatos «acuchillados» y algo particularmente curioso; una vieja capa que en ambos casos está tan deteriorada que solo servirá como «soletas» de calzas.

\subsection{Protagonistas pícaras}

Si los datos históricos nos aproximan a la primera década del siglo XVII, y parece obvio que el "pícaro" ya estaba consolidado entonces como prototipo social bien definido, es muy probable que el autor tuviese conocimiento de la producción literaria en que aparecían protagonistas pícaras y que quisiese construir sus personajes femeninos en esa misma línea. Téngase en cuenta que La Pícara Justina se publica en 1605.

En este sentido ya he tratado en otro lugar sobre la similitud existente entre las protagonistas femeninas de la Tragicomedia de Polidoro y Casandrina con algunas féminas de la picaresca. En concreto la alcahueta y hechicera Corneja, antigua discípula de Elicia, y su hija Casandrina (una cantonera, o prostituta clandestina), que distan mucho de aquellas protagonistas nobles o aristocráticas de las continuaciones anteriores y que, sin embargo, están más próximas a La Ingeniosa Elena, de Salas Barbadillo (1614). En dicha obra aparece un relato acerca de una familia de prostitutas, en el que se destacan los consejos de las madres a sus hijas para que ejerzan bien la prostitución. ${ }^{24}$

24.- Carmen Solana Segura, "La Tragicomedia de Polidoro y Casandrina como distorsión del paradigma celestinesco", Actas del I Congreso Internacional de Filología Hispánica, Jóvenes Investigadores (8 al 11 de mayo 2006 Oviedo), Coord. José Antonio Calzón, Oviedo, Ediciones de la Universidad de Oviedo, 2008, pp. 899-914. 
Tampoco encontramos a un padre obsesionado con salvaguardar la honra de su hija, como Teophilón en la Policiana. Por otro lado, al no centrar sus expectativas en el matrimonio, en todo momento el amor de los protagonistas es ilícito. Especialmente relevante es el hecho de que a ellas no les afecte el fin trágico que sufren el resto de los personajes. Salen airosas y enriquecidas con el botín anhelado por los criados. No hay castigo divino, ni mitológico; ni siquiera una voz narrativa moralizante que haga reflexionar a los lectores, como ocurre en el caso de otras novelas picarescas, como en La Pícara Justina (1605).

Por tanto, podríamos pensar que las protagonistas femeninas de la Tragicomedia se amoldan más a los prototipos de la picaresca femenina que al resto de sus antecesoras celestinescas, herederas de la ficción sentimental.

\subsection{Personajes que parecen vestidos para representar una comedia}

En el Acto II se menciona la representación de una comedia como una activad programada dentro de la rutina de la ciudad. Este dato también puede ayudar a establecer la cronología. En la Novena Escena del Acto II el criado Rubineto reacciona con el siguiente comentario ante el aspecto de Tristán y Rufino:

RUBINETO.- ¡Valga el diablo al bellaco acemilero rasca caballos! ¿Y de cuándo acá tan grave? ¿Has de representar en alguna comedia que tan aderezado vienes? Anda, anda, bellaco, desnúdate ese sayo. Ponte en calzas y en jubón y mira por aquellas acémilas que no las han hoy echado de comer. Toma una almohaza en esas manos y haz de tu persona. ¿ No veis al otro asno de Rufino? Y que compuesto está. Válaos el diablo, bellacos, ¿habéis hoy de representar? Anda ve tú, maldito. Mira aquellos caballos que no hacen hoy todo el día sino relinchar. [f.68v]

Durante el Siglo de Oro toda manifestación teatral era conocida como "comedia", salvo los autos sacramentales. Así pues, el público acudía a la comedia, ya fuera lo representado drama o tragedia. Aunque no existiese aún un lugar preciso para representar una comedia, el hecho de que en el texto se atribuya un día determinado para las representaciones puede llevarnos a la conclusión de que tal vez ya existiese algún corral de comedias en la ciudad innominada donde se desarrolla la obra. De hecho, Valladolid contaba con el Corral de la Puerta de San Esteban en 1575. En cuanto a Madrid, los seis primeros corrales de comedias inaugurados fueron los siguientes: dos en la calle del Príncipe, el de la Pacheca (1574), el de la Cruz (1579), el de la calle del Lobo, llamado de la Puente (1566) 
y el de la calle del Sol (1565). En Toledo se abrió el Mesón de la Fruta en 1576, y en el Coso de Zaragoza se levantó un teatrillo en 1589. Todas estas ciudades podrían haber servido de escenario para la Tragicomedia y en cualquier caso los corrales ubicados en las mismas son posteriores a 1564.

\subsection{Elicia habia padecido catorce veces las bubas y el alférez Campuzano habia padecido catorce cargas de bubas.}

Esta curiosa similitud que veremos a continuación, y que ya presentamos anteriormente, nos hace plantearnos si el autor desconocido de la Tragicomedia habría leído la Novela del Casamiento engañoso de Cervantes y si, de ser así, tal vez quisiera dejar un recuerdo en su obra. En la Novela del Casamiento Engañoso el alférez Campuzano explica a su amigo el motivo de su «color»y «flaqueza». Dice: «... no tengo que decir sino que salgo de aquel hospital, de sudar catorce cargas de bubas que me echó a cuestas una mujer que escogí por mía, que non debiera». ${ }^{25}$

En la Tragicomedia de Polidoro y Casandrina también se hace una alusión a la sífilis de manera similar. Ante las acusaciones de Salustio acerca de la virginidad perdida de Casandrina, la vieja hechicera se defiende del siguiente modo:

CORNEJA.- Bien te dije yo que no habías de creerme, pues malos lobos te coman saco de malicias. ¿Piensas que es la mi Casandrina como la puta vieja de tu madre?, que antes que llegase a los quince años había tenido catorce veces las bubas. Bien dicen piensa el ladrón que todos son de su condición. Piensa, pues, lo que quisieres, que, si no me creyeres, no se me da nada. Que por aquesta alma pecadora que en ese caso que esta como cuando era de nueve años. [f.59 r]

\section{Conclusión}

Para resumir las consideraciones anteriores, diremos que por un lado tenemos la fecha aproximada que nos aportan los cinco datos históricos, entre la última década del siglo XVI y las dos primeras del siglo XVII. Este intervalo queda establecido por la fecha más tardía, 1590, que nos aporta el estudio del apartado 1.2 sobre la Corte en Valladolid, y por la fecha más reciente, la primera década del xVII, como se explica en el apartado 1.5. Por otro lado, los cinco datos literarios nos marcan una cronología 
muy similar, que va desde 1599 , cuando se consagra el término pícaro en el Guzmán, hasta 1626, fecha de la primera edición del Buscón. Aunque no hay que olvidar que la primera redacción de esta obra se sitúa en el bienio 1603-1604, mientras que la segunda lo hace entre 1609-1614.

Todo ello nos hace pensar que tal vez el autor fuera coetáneo de autores que cultivaron el género picaresco (Cervantes, Salas Barbadillo o Quevedo), y que por tanto conocería bien sus obras. De esta manera la influe cia de las mismas quedaría plasmada en la Tragicomedia, creando así una especie de híbrido entre «celestinesca» ${ }^{26}$ y picaresca.

\section{Bibliografía}

Albi de la Cuesta, Julio, De Pavía a Rocroy. Los Tercios de Infantería Española en los siglos XVI y XVII, Balkan, Madrid, 1999.

Arata, Stefano, "Una nueva Tragicomedia celestinesca del siglo XVI», Celestinesca, 12-1 (1988), pp. 45-50.

Bataillón, Marcel, Pícaros y Picaresca, Taurus, Madrid, 1982.

Bernat, G, La minería colonial en la América española, Publicación Digital, 2002.

Cervantes, Miguel de, Novelas Ejemplares, ed. J.B. Avalle-Arce, Clásicos Castalia, Madrid, 1987, 3 vols.

Cortejoso, L., «Los Hospitales de Valladolid en tiempos de Felipe iII", Archivos iberoamericanos de historia de la medicina, 12, 133, 1960.

—, «El archivo del Hospital de la Resurrección de Valladolid, incorporado al histórico provincial y universitario", Boletín de Anabad, 4, Año XX-VIII.

Fernández Álvarez y Díaz Medina, Historia de España. Los Austrias Mayores y la culminación del Imperio [1516-1598], Gredos, Madrid, 1987.

García Oro y M. J. Portela Silva, "Felipe il y el problema hospitalario: reforma y patronato", Cuadernos de Historia Moderna, 25 (2000), pp. 87-124.

Gutiérrez Alonso, J. y J. Martín González, Historia de Valladolid. IV. Valladolid en el siglo XVII, Valladolid, Ateneo, 1982.

De la Cal, J. C., "Las otras 'Perejiles'. 1.000 islas que valen un reino», El Mundo, Publicación Digital, (2002).

Quevedo, Francisco de, La Vida del Buscón, ed. Lázaro Carreter, Planeta, Barcelona, 1982.

Quatrefages, R., Los Tercios, Madrid, Fundación Universitaria Española, 1983.

26.- En la actualidad estoy trabajando bajo la dirección de Valentín Núñez Rivera (Universidad de Huelva) en una edición de la obra descubierta por Arata en 1988. Espero pues esclarecer el texto estableciendo comparaciones con la tradición anterior y con la producción literaria cercana a la misma. 
Ribot García, Valladolid, Corazón del Mundo Hispánico. Siglo XVI, Valladolid, Ateneo, 1981.

Rufrinato, Aldo, Las Dos Caras del Lazarillo, Castalia, Madrid, 2000.

RUTHERFORD, John, Breve historia del picaro preliterario, Oviedo, Universidad de Oviedo, 2001.

Sevilla, Florencio, La Novela Picaresca Española, Castalia, Madrid, 2001.

Solana Segura, C., "La Tragicomedia de Polidoro y Casandrina como distorsión del paradigma celestinesco", Actas del I Congreso Internacional de Filología Hispánica, Jóvenes Investigadores (8 al 11 de mayo 2006 Oviedo), Coord. José Antonio Calzón, Oviedo, Ediciones de la Universidad de Oviedo, 2008, pp. 899-914.

Tragicomedia de Polidoro y Casandrina, ms. de la Biblioteca Real, sign. II1591.

Vian Herrero, Ana, "La Tragicomedia de Polidoro y Casandrina: relación cíclica y caminos de la parodia», Criticón 87-88-89 (2003), pp. 899-914.

VILAR, Pierre, Oro y moneda en la Historia 1450-1920, Barcelona, Ariel, 1974.

Wattenberg, Federico, Valladolid. Desarrollo del núcleo urbano de la ciudad desde su fundación hasta el fallecimiento de Felipe II, Valladolid, Ateneo, 1975.

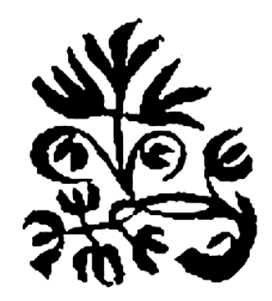


Solana Segura, Carmen, «Hacia una datación de la Tragicomedia de Polidoro y Casandrina: datos históricos e influencias literarias», Celestinesca, 33 (2009), pp. 217-231.

\section{RESUMEN}

La Tragicomedia de Polidoro y Casandrina, quinta continuación celestinesca, fue datada por Stefano Arata en 1564. Sin embargo, analizando cinco datos históricos que aparecen en la obra y otros cinco datos literarios, tres de los cuales entran en relación directa con la picaresca, podemos establecer una fecha de composición más tardía, probablemente entre la última década del siglo XVI y la primera del XVII.

palabras Clave: Tragicomedia de Polidoro y Casandrina, Hospital de la Resurrección, Picaresca.

\section{RESUMÉE}

La Tragicomedia de Polidoro y Casandrina, cinquième oeuvre "celestinesca", a été datée par Stefano Arata en 1564. Pourtant, en analiser cinq références historiques qui sont dans l'oeuvre et autres cinq références littéraires, trois de lesquelles ont une relation directe avec la picaresque, nous pouvons établir une date de composition plus éloignée, probablement entre la dernière décade du XVI ${ }^{\text {ème }}$ siècle et la première moitiè du XVII ${ }^{\mathrm{ème}}$ siècle.

KEY WORDS: Tragicomedia de Polidoro y Casandrina, Hospital de la Resurrección, Picaresque.

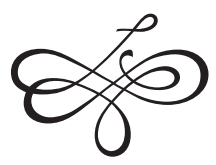

